\title{
Polarization independent and temperature tolerant AWG based on a silicon nitride platform
}

\author{
Sylvain Guerber ${ }^{1,{ }^{*},}$, Carlos Alonso-Ramos ${ }^{1}$, Xavier Le Roux $^{1}$, Nathalie \\ VUlliet $^{2}$, ERIC CASSAN ${ }^{1}$, Delphine MARris-Morini ${ }^{1}$, Frederic BoeUf ${ }^{2}$ AND \\ LAURENT VIVIEN ${ }^{1}$ \\ ${ }^{1}$ Université Paris-Saclay, CNRS, Centre de Nanosciences et de Nanotechnologies (C2N), 10 boulevard Thomas Gobert, 91120 Palaiseau, France \\ ${ }^{2}$ STMicroelectronics SAS -850 rue Jean Monnet-38920 Crolles, France \\ + Now with University Grenoble Alpes, CEA-LETI, 38000 Grenoble, France \\ *Corresponding author: sylvain.guerber@cea.fr
}

\begin{abstract}
Polarization tolerant optical receiver is a key building block for the development of wavelength division multiplexing (WDM) based high-speed optical data links. However, the design of polarization independent demultiplexer (DEMUX) is not trivial. In this work, we report on the realization of a polarization tolerant arrayed waveguide grating (AWG) on a $300-\mathrm{mm}$ silicon nitride (SiN) photonics platform. By introducing a series of individual polarization rotators in the middle of the waveguide array, the polarization dependence of the AWG has been substantially reduced. Insertion losses below $2.2 \mathrm{~dB}$ and a crosstalk level better than $-29 \mathrm{~dB}$ has been obtained for TE and TM polarizations on a four channel coarse AWG. The AWG temperature sensitivity has also been evaluated. Thanks to the low thermo-optical coefficient of SiN, a thermal shift below $12 \mathrm{pm} /{ }^{\circ} \mathrm{C}$ has been demonstrated.
\end{abstract}

\section{(C) 2020 Optical Society of America}

http://dx.doi.org/10.1364/OL.99.099999

\section{Introduction}

Leveraging the low cost and industrial manufacturing infrastructure of CMOS electronics, silicon photonics ( $\mathrm{SiPh}$ ) appear as a promising technology for the realization of efficient optical data links [1]. In particular, the integration of hundreds of optical components on a single chip can support the development of low cost coarse wavelength division multiplexing (CWDM), enabling the transmission of several high-speed data channels on a single optical fiber [2]. However, polarization management on the receiver side is a critical functionality, as commercially deployed optical fiber does not maintain the injected polarization state. A common solution consists of using a polarization splitter - rotator [3] at the receiver input to separate the transverse electric (TE) and transverse magnetic (TM) polarizations as well as rotating the TM(TE) signal into TE(TM). Therefore, two identical single polarization demultiplexer (DEMUX) can be used [4]. This approach simplifies the DEMUX design, but leads to a significantly larger footprint and increasing circuit complexity due to the multiplication of the components. Otherwise, a simpler solution is to use polarization tolerant DEMUX. Among all types of DEMUX, the arrayed waveguide grating (AWG) is particularly attractive with its potential for low insertion losses [5] and high channel count capacity [6]. Few methods have been proposed to reduce the polarization sensitivity of AWGs. The simplest strategy is to use a custom waveguide geometry in order to equalize the TE and TM effective indexesin the waveguide [7]. Another possibility exploits the intrinsic dependence of the waveguide birefringence to the waveguide width in order to reduce the polarization dependence of the AWG $[8,9]$. Despite the ease of implementation (no additional fabrication steps), these techniques critically rely on the precision of the patterning, any inaccuracies quickly lead to increased insertion losses as well as higher crosstalk levels. Moreover, due to material and waveguide dispersion, birefringence tailoring is only valid for a narrow spectral range prohibiting the use of such methods for large band width devices such as coarse wavelength division multiplexing based AWGs $(\Delta \lambda>100 \mathrm{~nm})$ [10]. Another interesting approach consists of introducing a half-wave plate in the middle of the AWG $[11,12]$. By doing so, the optical path for both polarizations will be perfectly equalized despite the inherent birefringence of the waveguides and star coupler slab regions. However, the insertion of such a plate leads to complex additional fabrication steps as well as high radiation losses especially for small (i.e. high index contrast) waveguides.

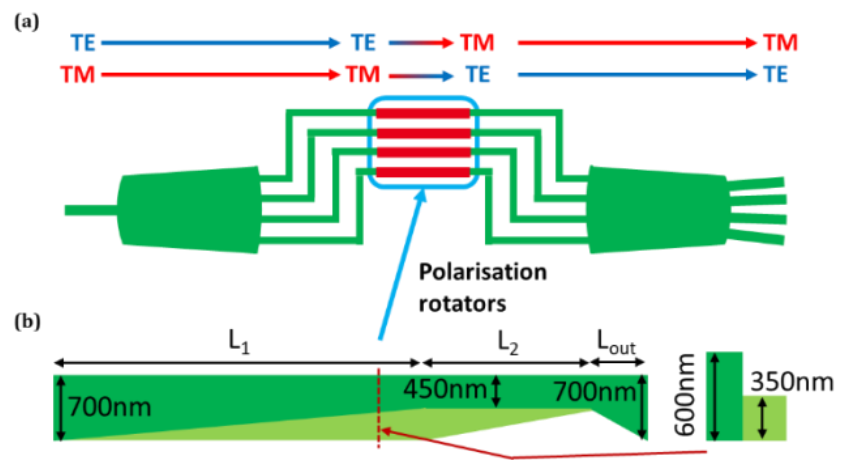

Fig. 1. (a) Top view of the AWG with integrated polarization rotators. The evolution of the input signal TE and TM components through the device is also shown. (b) Top and cut view of the SiN polarization rotator with all of its dimensions.

In this work, we propose a novel interpretation of this latter concept. As presented in Fig. 1(a), the half-wave plate is replaced by a series of individual waveguide-type polarization rotators (PR). Due to the proximity between the waveguides in the array, the fabrication dispersion between the rotators has to be low. Taking benefits from the excellent optical properties of silicon nitride (SiN) 
based waveguides (one order of magnitude lower thermo-optical coefficient and reduced index contrast compared to silicon [13]), a polarization independent four channel CWDM based SiN AWG targeting O-band operation has been experimentally demonstrated as a proof of concept.

\section{Polarization rotator}

Following the four channel CWDM standard, the proposed AWG is intended to operate over a large spectral range $(\sim 80 \mathrm{~nm})$. Therefore, in order to ensure low loss and broadband operation, a mode-evolution based architecture has been chosen for the polarization rotator [14]. This device is presented in Fig. 1(b). Unlike other common geometries, this PR is always narrower than the standard waveguide guaranteeing that PRs in the dense waveguide array do not overlap. In order to obtain polarization rotation, a vertical asymmetry in the waveguide geometry is required. In our $\mathrm{PR}$, this is implemented using a slab created by partial etching of the SiN film. The introduction of this additional level is justified since it can also be used on several other devices including star couplers [15], grating couplers [16] or rib waveguides [17]. As shown in Fig. 1(b), the SiN waveguide core is $600 \mathrm{~nm}$ height while the slab thickness is $350 \mathrm{~nm}$.

The polarization rotator design process starts by selecting the width of its sections. The input and output waveguides width is set to $700 \mathrm{~nm}$, which corresponds to the standard waveguide width in our platform [18] in order to facilitate the connection with the AWG. The intermediate rib width is set to $450 \mathrm{~nm}$ so that it is narrower than its height avoiding index crossing between the modes. During the first two sections of length $\mathrm{L}_{1}$ and $\mathrm{L}_{2}$, the optical axis of the waveguide will gradually rotate thanks to the vertical and lateral asymmetry. Using long enough waveguide sections within the PR will prevent from high insertion losses due to parasitic coupling with other modes.

The polarization rotator has been simulated using an eigen mode expansion (EME) solver [19], which is well suited for such longitudinal structures as it requires less computational resources than the more commonly used finite difference time domain (FDTD) method. Firstly, the rotator has been optimized by varying the length of both tapered sections $\mathrm{L}_{1}$ and $\mathrm{L}_{2}$ while Lout is set to $20 \mu \mathrm{m}$. The results are presented in Fig. 2(a). Assuming a similar behavior for the opposite conversion, the graph shows the TM to TE rotation efficiency (i.e. transmission) as a figure of merit for the optimization. As it can be seen, a conversion efficiency higher than $99 \%$ is obtained for $\mathrm{L}_{1}=26 \mu \mathrm{m}$ and $\mathrm{L}_{2}=80 \mu \mathrm{m}$. As shown in Fig. 2(b) (dashed lines), this optimized PR demonstrates a wavelength tolerant behavior with an extinction ratio (ER) higher than $20 \mathrm{~dB}$ over more than $80 \mathrm{~nm}$ for both TE and TM polarizations.

The device was fabricated on the $300 \mathrm{~mm}$ silicon photonics R\&D platform in ST Crolles (France). More details about it can be found in $[18,20]$. Characterization has been performed using an edge coupling scheme as described in [21]. The control of light polarization state has been performed using standard fiber paddle polarization controller together with calcite-made polarizers and polarization maintaining optical fibers in order to proper reject the unwanted polarization states on a large wavelength range.

The accurate extraction of the insertion losses of the PR has been done using the cutback method using the transmission of waveguides containing 2, 4 and 6 polarization rotators. Thus, assuming a similar conversion efficiency, the measured insertion losses are an averaging of the rotator TE to TM and TM to TE transmission. Since the fiber-chip coupling efficiency depends on the light polarization, we chose to use an even number of PR so that the light polarization at the input fiber-chip coupler and at the output one is the same, thus simplifying the normalization. As presented by the grey curve Fig. 2(b), the insertion loss of the rotator is better than $-0,5 \mathrm{~dB}$ over the whole 0 -band. The additional loss compared to simulation is attributed to fabrication variations.

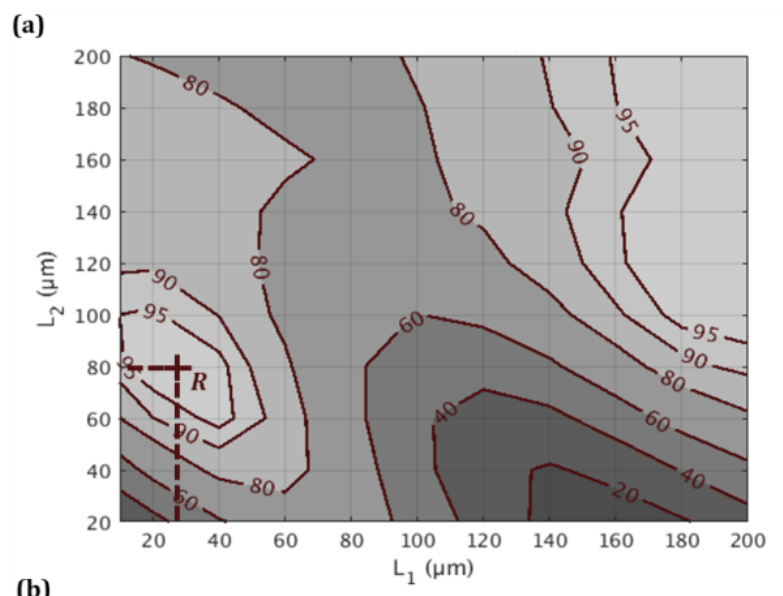

(b)

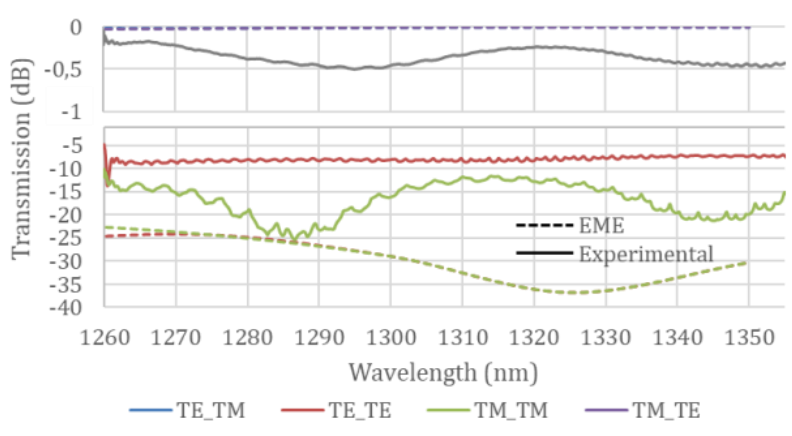

Fig. 2. (a) Simulation (EME) of the TM to TE rotation efficiency as a function of $\mathrm{L}_{1}$ and $\mathrm{L}_{2}$ at a wavelength of $1300 \mathrm{~nm}$. (b) Simulated (dashed lines) and experimental (solid lines) spectral response of the polarization rotator. The solid grey line represents the experimental transmission of the PR. Vertical axis have been splitted with two different scales for better visibility of the top curves.

An extinction ratio higher than $7 \mathrm{~dB}$ has been measured on a waveguide containing a single rotator. This deviation compared to simulation $(E R>20 \mathrm{~dB})$ is attributed to the poor extinction ratio of the measurement bench. Indeed, we believe that the PR has a higher ER than the measured value since there is no parasitic transmission peaks on the AWG spectrum (as can be seen in the next section) that could be attributed to residual non-rotated light.

\section{Arrayed waveguide grating}

The working principle of an AWG has been extensively described in the literature [22]. Here we present the simple design procedure that we followed for the four channel CWDM SiN based AWG.

First, the array order has been set to $\mathrm{m}=6$ as a compromise between the channel transmission non-uniformity and the array diffraction efficiency (which ultimately defines the device footprint) [23]. Then, the path length difference between the arms of the array, 
$\Delta \mathrm{L}$, can be calculated. Taking into account that the incoming light will pass through half of the array in TE(TM) and the other half in $\mathrm{TM}(\mathrm{TE})$, we found $\Delta \mathrm{L}=4.675 \mu \mathrm{m}$. The array waveguides and injection/collection waveguides are connected to the star couplers using tapers (width $\mathrm{W}_{\mathrm{ar}}=3 \mu \mathrm{m}, \mathrm{W}_{\mathrm{inj} / \mathrm{col}}=6 \mu \mathrm{m}$ ). Thus, the index contrast between taper and star couplers is reduced, prohibiting back light reflection and noise. In order to minimize the insertion losses of the device, the spacing between the tapers in the array is set to $200 \mathrm{~nm}$ that is the minimum feature size allowed in our fabrication process. Therefore, the waveguide pitch in the array is $\mathrm{d}_{\mathrm{ar}}=3.2 \mu \mathrm{m}$. Using all these parameters, the array dispersion can be calculated [22]. A star coupler radius of $R=500 \mu \mathrm{m}$ has been chosen so that the spacing between the output waveguides is large enough $\left(d_{r}=12.4 \mu \mathrm{m}\right)$ to avoid parasitic coupling. As depicted in Fig. 3(a), the same partial etching step as the one used for the polarization rotator has been performed at both end of the star couplers in order to reduce the index contrast between the slab mode propagating in the star coupler and the taper modes, which will further reduce the device insertion loss [15]. Using finite difference time domain (FDTD) simulations [19], the input waveguide diffraction angle has been estimated at $17^{\circ}$. From these parameters, the number of waveguides in the array has been fixed to $\mathrm{N}=48$ in order to collect all the light coming from the input waveguide. The AWG parameters are summarized in table 1. Due to the lowarray order, and therefore short $\Delta \mathrm{L}$, an "omega" array shape has been chosen in order to keep sufficient spacing between waveguides in the array. The fabricated AWG as well as the series of polarization rotators can be seen on Fig. 3(a).

Table 1. AWG parameters.

\begin{tabular}{ccc}
\hline Symbol & Description & Value \\
\hline $\mathrm{m}$ & Array order & 6 \\
\hline$\Delta \mathrm{L}$ & Path length difference & $4.675 \mu \mathrm{m}$ \\
\hline $\mathrm{W}_{\mathrm{ar}}$ & Array taper width & $3 \mu \mathrm{m}$ \\
\hline $\mathrm{W}_{\mathrm{in} / \mathrm{col}}$ & In/out taper width & $6 \mu \mathrm{m}$ \\
\hline $\mathrm{d}_{\mathrm{ar}}$ & Array waveguide pitch & $3.2 \mu \mathrm{m}$ \\
\hline $\mathrm{R}$ & Star coupler radius & $500 \mu \mathrm{m}$ \\
\hline $\mathrm{d}_{\mathrm{r}}$ & In/out waveguide pitch & $12.4 \mu \mathrm{m}$ \\
\hline $\mathrm{N}$ & Number of array waveguide & 48 \\
\hline- & Footprint & $2200 \times 470 \mu \mathrm{m}$ \\
\hline
\end{tabular}

The normalized experimental transmission of the AWG is shown Fig. 3(b). First, the measured transmission of the AWG is normalized using the transmission of a straight $\mathrm{SiN}$ waveguide containing a single rotator. This will filter the different coupling losses (due to opposite polarizations) at the input and output fibre - chip couplers as well as the experimental setup transmission. The normalized insertion losses of the AWG is then obtained by adding the insertion losses of the PR. As shown on Fig. 3(b), the four channels present insertion losses below $2.1 / 1.4 \mathrm{~dB}, 1.4 / 1.2 \mathrm{~dB}$, $1.9 / 2.1 \mathrm{~dB}, 1.1 / 1.6 \mathrm{~dB}$ for the TE/TM polarization and a crosstalk level higher than $30.3 / 31.4 \mathrm{~dB}, 30.1 / 30.5 \mathrm{~dB}, 31.3 / 29.7 \mathrm{~dB}$, 31.5/29.3dB. Furthermore, no significant spectral shift can be seen between the TE and TM response. As a reference, the transmission of a channel from a similar AWG without polarization rotators inserted in the waveguide array is also presented (dashed colored lines). As shown, such AWG presents $\sim 7 \mathrm{~nm}$ peak shift between TE and TM polarizations. (a)

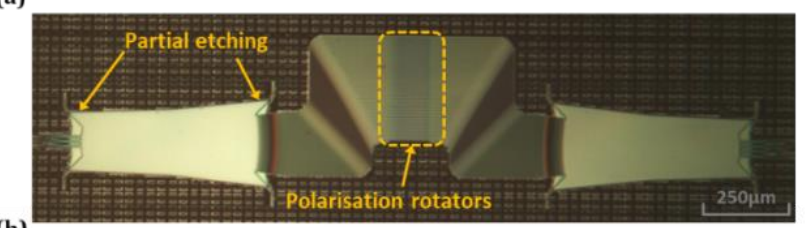

(b)

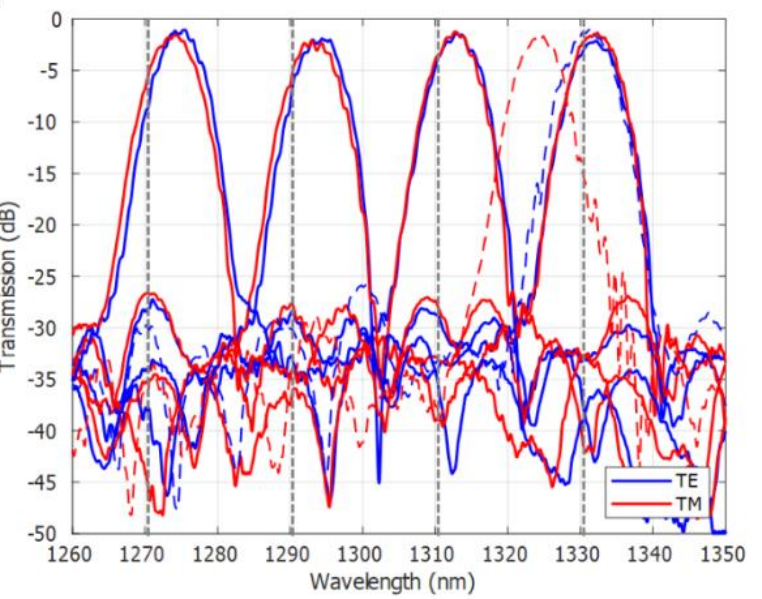

Fig. 3. (a) Optical microscope top view of the AWG. (b) Experimental transmission of the four channels of the AWG for both TE and TM polarizations. The transmission of a channel from a reference AWG is also shown in colored dashed lines. The grey dashed lines correspond to the channel positions according to the CWDM standard.

In addition to polarization tolerance, demultiplexer designed for CWDM transceivers require temperature independent operation. Therefore, the temperature dependence of the AWG has also been evaluated using a Peltier element to control the chip temperature. As shown on Fig. $4(\mathrm{a})$, temperature was varied between $20^{\circ} \mathrm{C}$ to $45^{\circ} \mathrm{C}$ with $5^{\circ} \mathrm{C}$ steps. Using a linear interpolation, a low thermal drift of $11.9 \mathrm{pm} /{ }^{\circ} \mathrm{C}$ has been extracted (Fig. 4(b)), which corresponds to a shift below $1 \mathrm{~nm}$ for $\Delta \mathrm{T}=80^{\circ} \mathrm{C}$. This value is in good agreement with other SiN based devices reported in the literature $[13,24]$.

\section{Conclusion}

By introducing an array of individual waveguide-type polarization rotators, a polarization independent CWDM silicon nitride based AWG has been demonstrated with interesting characteristics in terms of insertion loss and crosstalk. Compared to other methods, this technique allows for the reduction of the polarization dependence of an AWG over a large spectral range, paving the way to the realization of efficient polarization insensitive CWDM receivers. 
(a)

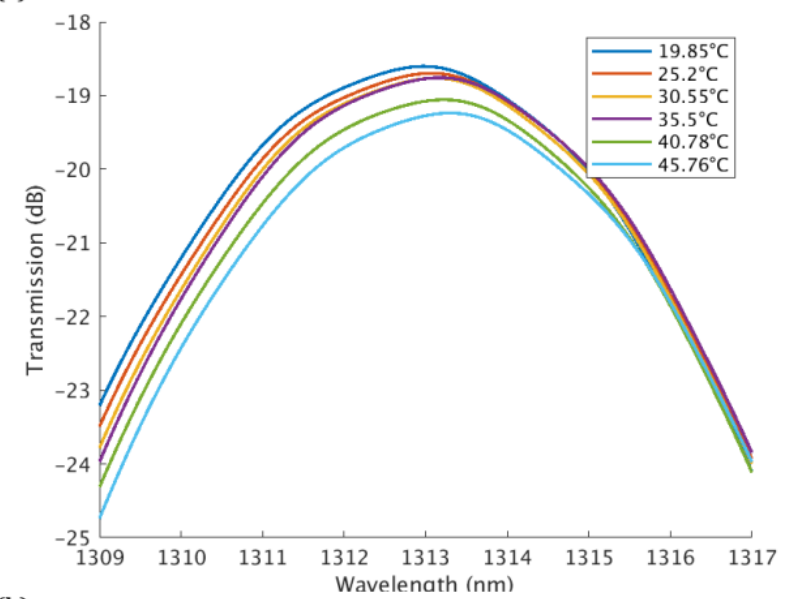

(b)

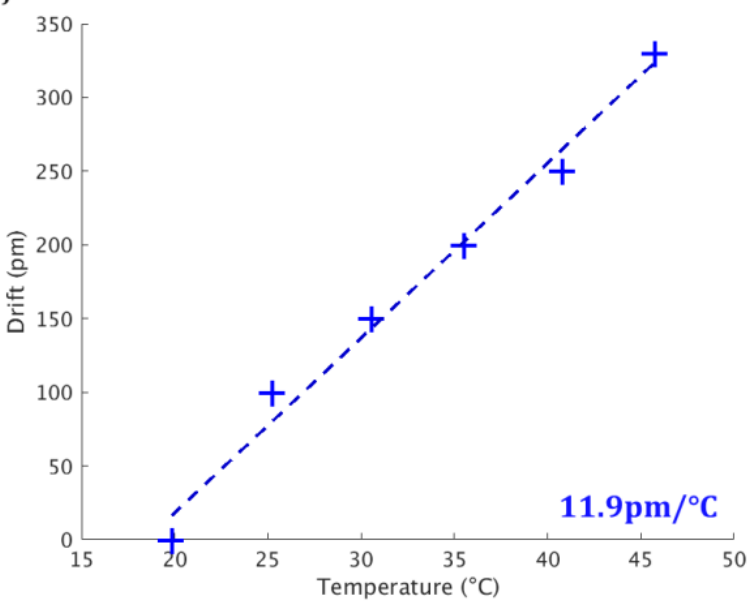

Fig. 4. (a) Measured transmission of a central channel of the AWG at different temperatures in TE polarization. (b) Extracted AWG response drift with temperature.

Funding. This work was supported in part by the European Research Council (ERC POPSTAR) under Grant 647342, in part by the European Commission H2020-ICT-27-2015 (COSMICC) under Grant 688516 and in part by the French Industry Ministry Nano program.

Disclosures. The authors declare no conflicts of interest.

Acknowledgments. The authors would like to sincerely thank Dr Charles Baudot for his large and valuable contribution to this work, as well as Daniel Benedikovic, Elena Durán-Valdeiglesias, Joan Manel Ramirez and the ST Crolles manufacturing team.

\section{References}

1. X. Chen, M. M. Milosevic, S. Stankovic, S. Reynolds, T. D. Bucio, K. Li, D. J. Thomson, F. Gardes and G. T. Reed, in Proceedings of the IEEE, vol. 106, no. 12, pp. 2101-2116, Dec. 2018.

2. J. B. Driscoll, P. Doussiere, S. Islam, R. Narayan, W. Lin, H. Mahalingam, J. S. Park, Y. Lin, K. Nguyen, K. Roelofs, A. Dahal, R. Venables, L. Liao, R. Jones, D. Zhu, S. Priyadarshi, B. Parthasarathy and Y. Akulova, in Proc. IEEE-GFP, Cancun, Mexico, Aug. 2018, pp. 1-2.
3. W. D. Sacher, T. Barwicz, B. J. F. Taylor and J. K. S. Poon, Opt. Express, vol. 22, no. 4, pp. 3777-3786, 2014.

4. S.-H. Jeong, Y. Onawa, D. Shimura, H. Okayama, T. Aoki, H. Yaegashi, T. Horikawa and T. Nakamura, ECOC, Dublin, Ireland, Sept. 2019, pp. 1-4.

5. K. Shang, S. Pathak, C. Qin and S. J. B. Yoo, in IEEE Photonics Journal, vol. 9, no. 5, pp. 1-5, 2017.

6. S. Cheung, T. Su, K. Okamoto and S. J. B. Yoo, in IEEE JSTQE, vol. 20, no. 4, pp. 310-316, 2014.

7. J. H. den Besten, M. P. Dessens, C. G. P. Herben, X. J. M. Leijtens, F. H. Groen, M. R. Leys and M. K. Smit, in IEEE PTL, vol. 14, no. 1, pp. 62-64, 2002.

8. Y. Inoue, M. Itoh, Y. Hashizume, Y. Hibino, A. Sugita and A. Himeno, OFC, Anaheim, USA, March 2001, pp. WB4-WB4.

9. T. Lang, J.-J. He, J.-G. Kuang and S. He, Opt. Express, vol. 15, no. 23, pp. 15022-15028, 2007.

10. W.-C. Kim, Y.-S. Kim, S.-Y. Kim, Y.-C. Noh, Y.-K. Song, S.-H. Kang, J.-G. Pyo and J.-B. Kim, in Opt. Eng., vol. 55, no. 8, 2016.

11. H. Takahashi, Y. Hibino and I. Nishi, Opt. Lett., vol. 17, no. 7, pp. 499501, 1992.

12. Y. Inoue, Y. Ohmori, M. Kawachi, S. Ando, T. Sawada and H. Takahashi, in IEEE PTL, vol. 6, no. 5, pp. 626-628, 1994.

13. Q. Wilmart, H. El Dirani, N. Tyler, D. Fowler, S. Malhouitre, S. Garcia, M. Casale, S. Kerdiles, K. Hassan, C. Monat, X. Letartre, A. Kamel, M. Pu, K. Yvind, L. K. Oxenløwe, W. Rabaud, C. Sciancalepore, B. Szelag and S. Olivier, in MDPI Appl. Sci., vol. 9, no. 2, 2019.

14. K. Goi, A. Oka, H. Kusaka, K. Ogawa, T.-Y Liow, X. Tu, G.-Q. Lo and D.-L. Kwong, Opt. Lett., vol. 40, no. 7, pp. 1410-1413, 2015.

15. W. Bogaerts, S. K. Selvaraja, P. Dumon, J. Brouckaert, K. D. Vos, D. V. Thourhout and R. Baets, in IEEE JSTQE, vol. 16, no. 1, pp. 33-44, 2010.

16. D. Benedikovic, C. Alonso-Ramos, D. Pérez-Galacho, S. Guerber, V. Vakarin, G. Marcaud, X. Le Roux, E. Cassan, D. Marris-Morini, P. Cheben, F. Boeuf, C. Baudot and L. Vivien, Opt. Lett., vol. 42, no. 17, pp. 34393442, 2017.

17. S. K. Selvaraja, W. Bogaerts, P. Absil, D. V. Thourhout and R. Baets, in Proc. IEEE-GFP, New York, USA, 2010.

18. S. Guerber, C. Alonso-Ramos, D. Benedikovic, D. Pérez-Galacho, X. Le Roux, N. Vulliet, S. Crémer, L. Babaud, J. Planchot, D. Benoit, P. Chantraine, F. Leverd, D. Ristoiu, P. Grosse, D. Marris-Morini, L. Vivien, C. Baudot and F. Boeuf, in Proc. SPIE 10686, Strasbourg, France, 2018.

19. Lumerical Solutions, Inc. Photonic Component \& Circuit Design Software. Accessed: Jul. 31, 2020. [Online]. Available: https://www.lumerical.com/products/

20. F. Boeuf, A. Fincato, L. Maggi, J.F. Carpentier, P. Le Maitre, M. Shaw, S. Cremer, N. Vulliet, C. Baudot, S.Monfray, S. Jan, C. Deglise, J.R. Manouvrier, C.Durand, A. Simbula, D. Goguet, P. Bar, D. Ristoiu, F. Leverd, L. Babaud, A. Daverio, M.Binda, A. Bazzotti, A. Canciamilla, L. Ramini, M.Traldi, P. Gambini, in IEEE-IEDM, San Francisco, USA, Dec. 2019, pp. 33.1.1-33.1.4.

21. S. Guerber, C. Alonso-Ramos, D. Benedikovic, E. Durán-Valdeiglesias, X. Le Roux, N. Vulliet, E. Cassan, D. Marris-Morini, C. Baudot, F. Boeuf and L. Vivien, in IEEE PTL, vol. 30, no. 19, pp. 1679-1682, 2018.

22. M. K. Smit and C. V. Dam, in IEEE JSTQE, vol. 2, no. 2, pp. 236 - 250, 1996.

23. S. Pathak, D. Van Thourhout and W. Bogaerts, Opt. Lett., vol. 38, no. 16, pp. 2961-2964, 2013.

24. E. Durán-Valdeiglesias, S. Guerber, D. Oser, X. Le Roux, D. Benedikovic, D. Pérez-Galacho, N. Vulliet, S. Cremer, S. Monfray, E. Cassan, D. MarrisMorini, C. Baudot, F. Boeuf, L. Vivien and C. Alonso-Ramos, Opt. Lett., vol. 44, no. 18, pp. 4578-4581, 2019. 


\section{Full references}

1. X. Chen, M. M. Milosevic, S. Stankovic', S. Reynolds, T. D. Bucio, K. Li, D. J. Thomson, F. Gardes and G. T. Reed, "The Emergence of Silicon Photonics as a Flexible Technology Platform," in Proceedings of the IEEE, vol. 106, no. 12, pp. 2101-2116, Dec. 2018.

2. J. B. Driscoll, P. Doussiere, S. Islam, R. Narayan, W. Lin, H. Mahalingam, J. S. Park, Y. Lin, K. Nguyen, K. Roelofs, A. Dahal, R. Venables, L. Liao, R. Jones, D. Zhu, S. Priyadarshi, B. Parthasarathy and Y. Akulova, "First 400G 8-Channel CWDM Silicon Photonic Integrated Transmitter," in Proc. IEEE-GFP, Cancun, Mexico, Aug. 2018, pp. 1-2.

3. W. D. Sacher, T. Barwicz, B. J. F. Taylor and J. K. S. Poon, "Polarization rotator-splitters in standard active silicon photonics platforms," Opt. Express, vol. 22, no. 4, pp. 3777-3786, 2014.

4. S.-H. Jeong, Y. Onawa, D. Shimura, H. Okayama, T. Aoki, H. Yaegashi, T. Horikawa and T. Nakamura, "Silicon photonics based 16 $\lambda$-WDM demultiplexers for operating in C-band and O-band spectral regimes," ECOC, Dublin, Ireland, Sept. 2019, pp. 1-4.

5. K. Shang, S. Pathak, C. Qin and S. J. B. Yoo, "Low-Loss Compact Silicon Nitride Arrayed Waveguide Gratings for Photonic Integrated Circuits," in IEEE Photonics Journal, vol. 9, no. 5, pp. 1-5, 2017.

6. S. Cheung, T. Su, K. Okamoto and S. J. B. Yoo, "Ultra-Compact Silicon Photonic $512 \times 51225 \mathrm{GHz}$ Arrayed Waveguide Grating Router," in IEEE JSTQE, vol. 20, no. 4, pp. 310-316, 2014.

7. J. H. den Besten, M. P. Dessens, C. G. P. Herben, X. J. M. Leijtens, F. H. Groen, M. R. Leys and M. K. Smit, "Low-loss, compact, and polarization independent PHASAR demultiplexer fabricated by using a double-etch process," in IEEE PTL, vol. 14, no. 1, pp. 62-64, 2002.

8. Y. Inoue, M. Itoh, Y. Hashizume, Y. Hibino, A. Sugita and A. Himeno, "Novel birefringence compensating AWG design," OFC, Anaheim, USA, March 2001, pp. WB4-WB4.

9. T. Lang, J.-J. He, J.-G. Kuang and S. He, "Birefringence compensated AWG demultiplexer with angled star couplers," Opt. Express, vol. 15, no. 23, pp. 15022-15028, 2007.

10. W.-C. Kim, Y.-S. Kim, S.-Y. Kim, Y.-C. Noh, Y.-K. Song, S.-H. Kang, J.-G. Pyo and J.-B. Kim, "Investigation of 18-channel CWDM arrayed waveguide grating with silica-based waveguide," in Opt. Eng., vol. 55, no. 8, 2016.

11. H. Takahashi, Y. Hibino and I. Nishi, "Polarization-insensitive arrayedwaveguide grating wavelength multiplexer on silicon," Opt. Lett., vol. 17, no. 7, pp. 499-501, 1992.

12. Y. Inoue, Y. Ohmori, M. Kawachi, S. Ando, T. Sawada and H. Takahashi, "Polarization mode converter with polyimide half waveplate in silicabased planar lightwave circuits," in IEEE PTL, vol. 6, no. 5, pp. 626-628, 1994.

13. Q. Wilmart, H. El Dirani, N. Tyler, D. Fowler, S. Malhouitre, S. Garcia, M. Casale, S. Kerdiles, K. Hassan, C. Monat, X. Letartre, A. Kamel, M. Pu, K. Yvind, L. K. Oxenløwe, W. Rabaud, C. Sciancalepore, B. Szelag and S. Olivier, "A Versatile Silicon-Silicon Nitride Photonics Platform for Enhanced Functionalities and Applications," in MDPI Appl. Sci., vol. 9, no. 2, 2019.

14. K. Goi, A. Oka, H. Kusaka, K. Ogawa, T.-Y Liow, X. Tu, G.-Q. Lo and D.-L. Kwong, "Low-loss partial rib polarization rotator consisting only of silicon core and silica cladding", Opt. Lett., vol. 40, no. 7, pp. 1410-1413, 2015.

15. W. Bogaerts, S. K. Selvaraja, P. Dumon, J. Brouckaert, K. D. Vos, D. V. Thourhout and R. Baets, "Silicon-on-Insulator Spectral Filters Fabricated With CMOS Technology," in IEEE JSTQE, vol. 16, no. 1, pp. 33-44, 2010.

16. D. Benedikovic, C. Alonso-Ramos, D. Pérez-Galacho, S. Guerber, V. Vakarin, G. Marcaud, X. Le Roux, E. Cassan, D. Marris-Morini, P. Cheben F. Boeuf, C. Baudot and L. Vivien, "L-shaped fiber-chip grating couplers with high directionality and low reflectivity fabricated with deep-UV lithography," Opt. Lett., vol. 42, no. 17, pp. 3439-3442, 2017.

17. S. K. Selvaraja, W. Bogaerts, P. Absil, D. V. Thourhout and R. Baets, "Record Low-Loss Hybrid Rib/Wire Waveguides for Silicon Photonic Circuits." in Proc. IEEE-GFP, New York, USA, 2010.
18. S. Guerber, C. Alonso-Ramos, D. Benedikovic, D. Pérez-Galacho, X. Le Roux, N. Vulliet, S. Crémer, L. Babaud, J. Planchot, D. Benoit, P. Chantraine, F. Leverd, D. Ristoiu, P. Grosse, D. Marris-Morini, L. Vivien, C. Baudot and F. Boeuf, "Integrated SiN on SOI dual photonic devices for advanced datacom solutions," in Proc. SPIE 10686, Strasbourg, France, 2018.

19. Lumerical Solutions, Inc. Photonic Component \& Circuit Design Software. Accessed: Jul. 31, 2020. [Online]. Available: https://www.lumerical.com/products/

20. F. Boeuf, A. Fincato, L. Maggi, J.F. Carpentier, P. Le Maitre, M. Shaw, S. Cremer, N. Vulliet, C. Baudot, S.Monfray, S. Jan, C. Deglise, J.R. Manouvrier, C.Durand, A. Simbula, D. Goguet, P. Bar, D. Ristoiu, F. Leverd, L. Babaud, A. Daverio, M.Binda, A. Bazzotti, A. Canciamilla, L. Ramini, M.Traldi, P. Gambini, "A Silicon Photonics Technology for 400 Gbit/s Applications, " in IEEE-IEDM, San Francisco, USA, Dec. 2019, pp. 33.1.1-33.1.4.

21. S. Guerber, C. Alonso-Ramos, D. Benedikovic, E. Durán-Valdeiglesias, X. Le Roux, N. Vulliet, E. Cassan, D. Marris-Morini, C. Baudot, F. Boeuf and L. Vivien, "Broadband Polarization Beam Splitter on a Silicon Nitride Platform for O-Band Operation," in IEEE PTL, vol. 30, no. 19, pp. 16791682, 2018.

22. M. K. Smit and C. V. Dam, "PHASAR-Based WDM-Devices: Principles, Design and Applications," in IEEE JSTQE, vol. 2, no. 2, pp. 236 - 250, 1996.

23. S. Pathak, D. Van Thourhout and W. Bogaerts, "Design trade-offs for silicon-on-insulator-based AWGs for (de)multiplexer applications," Opt. Lett., vol. 38, no. 16, pp. 2961-2964, 2013.

24. E. Durán-Valdeiglesias, S. Guerber, D. Oser, X. Le Roux, D. Benedikovic, D. Pérez-Galacho, N. Vulliet, S. Cremer, S. Monfray, E. Cassan, D. MarrisMorini, C. Baudot, F. Boeuf, L. Vivien and C. Alonso-Ramos, "Dualpolarization silicon nitride Bragg filters with low thermal sensitivity," Opt. Lett., vol. 44, no. 18, pp. 4578-4581, 2019. 